\title{
Assessment of Professional Nursing Governance among Egyptian Nurses
}

\author{
Safiya S. Sayed ${ }^{1}$, Manal Z. Ahmed ${ }^{2}$, Manal M. Bakr ${ }^{3}$, and Nabila M. Sherief ${ }^{4}$ \\ ${ }^{1}$ Assistant lecturer of Nursing Administration, ${ }^{2}$ Professor of Nursing Administration, ${ }^{3}$ Assistant \\ Professor of Nursing Administration, ${ }^{4}$ Lecturer of Nursing Administration, Faculty of Nursing, \\ Menoufia University
}

\begin{abstract}
Background: improving working environment of clinical nurses is a major issue faced by nurse managers and administrators who are challenged to create models of nursing governance and leadership strategies in order to engage clinical nurses in the work. Purpose: The purpose of this study was to identify the professional nursing governance in a selected hospital. Methods: A descriptive research design was conducted at Menoufia University hospital sampling: stratified random sample of 200 nurses were included. Results: The identified professional nursing governance was traditional governance. Conclusion: The lowest mean score was for shared governance among the majority of nurses. Recommendations: Hospital administrators must provide supportive organizational structures and leadership strategies to improve nursing staff involvement in job design, problem solving, conflict resolution, committees and organizational decision making as key component for productive organization in turn lead to safe work environment.
\end{abstract}

Keywords: Hospital, Nursing, Professional governance.

\section{Introduction}

In today's complex healthcare organizations, many challenges are faced such as nursing shortage, increased patient acuities, and increased regulations that led to nurses' workload, job dissatisfaction, and less time spent at the bedside. These challenges increase nurses' responsibilities and accountabilities but do not give power or authority to address the needed changes that affect nursing practice (World Health Organization, 2012). Healthcare managers and leaders understand that quality care is best delivered by staff nurses who are committed to the organization and empowered to practice their profession with no restraints and full autonomy through the implementation of professional nursing governance and shared governance models and creating an attractive work environment (Cohen, 2015).Healthcare organizations striving for the achievement of nursing excellence in professional practice through including and supporting shared governance in their strategic plan (Wilson, 2013).

Hess (2010) defined professional nursing governance as a multidimensional concept that includes the structure and process through which professional nurses direct, control and regulate the many goal-oriented efforts of their professional practice and influence the organizational context in which it occurs through organizational recognition, facilitating structures, the liaison of information and the alignment of goals. Professional nursing shared governance is the extension of power, control, and authority to the frontline staff nurses over their clinical practice (Hess et al., 2011). Shared governance is an ideal example of decentralization. It is described as an organizational innovation that gives healthcare professionals control over their practices and extends their influence into administrative areas previously controlled only by managers and supervisors (Swihart \& Hess, 2014). In a

shared governance environment, staff takes ownership of decision making. This is a dynamic staff-leadership partnership that promotes collaboration, shared decision making and accountability for improving quality of care, safety, and enhancing work life (Mathias, 2015).

\section{Purpose}

The purpose of this study was to identify the type of professional nursing governance used in the selected setting. 
Safiya S. Sayed, Manal Z. Ahmed, Manal M. Bakr, and Nabila M. Sherief" Assessment of Profession ..."

\section{Research question}

What is type of professional governance encountered by nurses in the selected setting?

\section{Methods}

\section{Research Design:}

A descriptive research design was used in this study.

\section{Setting:}

The study was conducted in general departments and closed units in Menoufia university hospital Menoufia governorate/ Egypt. This hospital provides comprehensive medical and surgical services for patients, teaching services for medical and nursing students in addition to research activities. This hospital contains four buildings, general hospital, emergency hospital specialized hospital and oncology hospital. The bed capacity of the hospital is 1000 beds. The occupancy rate of the hospital is $800-900$ patients/year.

\section{Sample}

Stratified random sample was used to recruit the sample for the current study from different buildings of the hospital. The sample was selected by dividing studied hospital into two strata (closed units and general ward) in each stratum ten percent of nurses were selected to participate in the study based on the monthly schedule (odd numbers were select).

The total number of nurses in the selected hospital was 1280 . The sample size was calculated utilizing $\mathrm{G}$ Power program, with a power of 0.95 , alpha of 0.05 , and a medium effect size. The minimum sample size required for Pearson Correlation analysis was 167 participants. The total sample size of the study was increased to 200 nurses to avoid the negative impact of attrition. Two hundred nurses who accepted to participate in the study constituted the study sample. Both male and female nurses who had at least one year of experience can read and understand English and accepted to participate in this study were invited to be part of the research. The distribution of study sample at the selected departments / units $(\mathrm{N}=200)$ : 49 nurses from general departments and 151 nurses from closed units with percentage of $(24.5 \%$ and $75.5 \%$ ) respectively.

\section{Instrument}

One instrument was used for data collection.

\section{Index of Professional Nursing Governance questionnaire (IPNG)}

This instrument was developed by Hess (1994) to measure nursing governance. It contains 86 questions. They were divided into six dimensions. Professional control contains 13 items, it measures who controls nursing personnel and related structures. Organizational influence contains 14 items; they are related to who influences practice. Official authority contains 22 items, it measures who controls professional practice. Participation contains 10 items, related to who participates in structures related to governance activities at different organizational levels. Access to information contains 15 items, related to who has access to information relevant to governance activities. Ability contains 12 items, related to who sets and negotiates the resolution of conflict at different organizational levels.

The total IPNG and subscales scores were computed using the IPNG scoring guidelines. Total mean score range from (86-430): Traditional Governance, a score of (86 to 172 ) is representative of management/administration input only; a score of (173 to 257) is representative of primarily management/administration with some staff input, a score of (258) is representative of equally shared by staff and management/administration (Shared Governance), and a score of (259 to 344) is representative of primarily staff with some management/administration input; and SelfGovernance: a score of (345 to 430) is representative of staff input only. Cronbach $\alpha$ of the total IPNG $(\alpha=0.97)$ and Cronbach's $\alpha$ for the 6 subscales ranges from (0.88 to 0.94). In the current study cronbach $\alpha$ of subscales were :( 0.79) for professional control, (0.80) for organizational influence, $(0.87)$ for official authority, (0.76) for participation (0.81) for access to information, and (0.76) for ability. Cronbach's $\alpha$ for the overall scale was (0.92). 


\section{Procedure}

An official letter was sent from the Dean of the faculty of nursing Menoufia University to the director of Menoufia University Hospital explaining the purpose and method of data collection. Self-administered questionnaire was used to collect data from respondents. The investigator explained the aim of the study to every participant. The investigator was available for help to avoid any misinterpretations of questions. An oral consent was taken from each study subject. Data collection took about four months from beginning of June to the end of September 2018.The questionnaires were distributed during nurse's work hours. It took around 25 minutes from each study sample to fill in the questionnaire.

\section{Ethical considerations}

Approval was obtained from the Ethics Committee of the Faculty of Nursing, Menoufia University. The privacy and confidentiality of data were maintained and assured by getting participants' consent to participate in the research before data collection. Anonymity of participants was granted.

\section{Statistical analysis}

Data was coded and transformed into specially designed form to be suitable for computer entry process. Data was entered and analyzed by using SPSS (Statistical Package for Social Science) statistical package version 23. Mean and standard deviation were done.

\section{Results}

Table 1: Represented percentage distribution of study sample according to their demographic characteristics. The table showed that the highest percentage of the study sample aged between 20 to 30 years $(67 \%)$ with mean age of (28.7). The highest percentage was for

Female $(76 \%)$. More than half of study sample had bachelor degree in nursing (52\%). More than three quarters of study sample worked in closed units $(75.5 \%)$. Regarding years of experience more than half of study sample $(55.5 \%)$ had less than five years of experience in nursing with mean experience of (4.7).

Table 1. Percentage distribution of study sample according to their demographic characteristics

\begin{tabular}{lcccc} 
& $(\mathrm{N}=200)$ & & & \\
\hline Demographic characteristics & No & $\%$ & & M \\
\hline Age (years) & 134 & & & \\
$20-30$ & 58 & 67 & 28.7 & \\
$31-40$ & 8 & 29 & & \\
$41-50$ & & 24 & \\
Gender & 48 & 76 & \\
$\quad$ Male & 152 & & \\
Female & & 45 & \\
Education & 90 & 52 & \\
Associate degree & 104 & 3 & \\
Bachelor & 6 & & \\
Master & 151 & 75.5 & \\
Unit & 49 & 24.5 & \\
Closed unites & & & \\
General Ward & 111 & 55.5 & \\
Experience & 48 & 24 & \\
$1-5$ & 34 & 17 & \\
$6-10$ & 7 & 3.5 & 4.7 \\
$11-15$ & 200 & 100 & \\
$16-25$ & & & \\
\hline Total & & & \\
\hline
\end{tabular}

Table 2: demonstrated mean score of IPNG among study nurses. As shown in the table more than two thirds (70\%) had traditional governance, while none had shared nor selfgovernance. This table indicated that the governance pattern which was used in the 
Safiya S. Sayed, Manal Z. Ahmed, Manal M. Bakr, and Nabila M. Sherief" Assessment of Profession ..." hospital is traditional (nursing management administration input only).

Table 2.Mean score of IPNG scoring among study nurses at selected setting ( $N=200)$

\begin{tabular}{lcccc}
\hline Group of shared governance & N & \% & M & SD \\
\hline Traditional governance (86 - 172). & 140 & $70 \%$ & 138.9 & 20.0 \\
$\begin{array}{l}\text { Primarily management/administrative with some staff } \\
\text { input (173-257). }\end{array}$ & 58 & $29 \%$ & 202.7 & 22.9 \\
Shared governance (258). & 0 & $0 \%$ & 0 & 0 \\
$\begin{array}{l}\text { Primarily staff with some management /administrative } \\
\text { input (259-344). }\end{array}$ & 2 & $1 \%$ & 273.0 & 9.8 \\
Self-Governance (Staff input only) (345-430). & & & & \\
\hline Total & 0 & $0 \%$ & 0 & 0 \\
\hline
\end{tabular}

Table 3: demonstrates Mean score of nursing governance was related to official Professional Nursing Governance subscales authority. While the lowest mean score (16.8) among nurses. As shown in the table the highest mean score (40.4) of professional was related to participation in organizational decisions

Table 3. Mean score of Professional Nursing Governance subscale among nurses

\begin{tabular}{lcc}
\hline Index Professional Nursing Governance (IPNG) subscale & M & SD \\
\hline Control over professional practice & 25.1 & 7.7 \\
Influence over resources & 24.1 & 6.6 \\
& & 11.8 \\
Official authority & 40.4 & 7.6 \\
Participation in organizational decisions & 16.8 & \\
& & 10.9 \\
Access to information & 30.1 & 9.8
\end{tabular}

Ability (goal Setting and conflict resolution)

22.3

Overall mean score of Professional Nursing Governance

158.7

50.7 


\section{Discussion}

Traditional governance was the governance pattern identified by nurses at Menofia University Hospital. This pattern of governance is the most common in Egypt especially in large healthcare institutions such as university hospitals .In addition, shared and selfgovernance patterns of governance are not yet used in Egyptian health care organizations. In this respect Toussaint \& Gerard, (2010) reported that traditional governance has proven to be a major flaw in healthcare management.

The result of the present study was supported by Wilson (2013) who conducted a study about evaluating shared governance for nursing excellence. The author reported that the organization has not yet achieved a baseline measurement within the shared governance range. In the overall governance scale, each of the studied three campuses scored below the minimum score of 173 , which places the organization in a state of traditional governance score range, where decisions were primarily made by management and administration only.

Also, the findings of the current study were consistent with Seada \& Etway( 2012) in study about Relationship between staff nurses' perception of professional shared governance and their job satisfaction. Study revealed that staff nurses had low perception of shared governance and indicated that they did not have professional control over their work environment.

Contradictory to the results of the present study, keane (2016) conducted study about the relationship between nurse manager leadership style and enculturation of shared governance. The result reported that over $85 \%$ of the respondents, in the study, scored within the shared governance range.
Also, findings of the current study were inconsistent with the findings of Hess et al. (2011) who conducted a study about Perceptions of nurses in Magnet hospitals, non-Magnet hospitals, and hospitals pursuing. The result reported that both direct care staff and leaders.

reported the presence of shared governance structures. Also, the result opposed to study by Clavelle et al. (2013), about structural empowerment and the nursing practice environment in Magnet organizations. The study reported presence of shared governance.

On the other hand, this study was in disagreements with the results of jones, (2017) who conducted a study about shared governance and organizational commitment.it was reported that there was strong shared governance in decision making.

The current study revealed that participation in organizational decisions had the lowest rating in nursing staff assessment of professional nursing governance elements. This could be due to the less involvement of nursing staff with hospital and nursing management in administrative decisions such as setting the hospital and work-related mission, philosophy, and goals as well as most of the conflict issues that are being solved by the management with little participation from nursing staff.

Similarly, Mahmoud (2016) conducted a study about relationship between nurses' professional shared governance and their work empowerment at Mansoura University and Specialized Medical Hospitals. Results stated that nurses could participate with nursing management/administration in clinical practice decisions; however, nurses had limited opportunities to participate in committees that relate to strategic planning, 
professionalism, and organizational budget.

Also, Kieft et al., (2014) conducted a qualitative study about how nurses and their work environment affect patient experiences of the quality of care: the study showed nurses are not always in charge and cannot every time make their own decisions about nursing issues. Additionally, they reported that if nurses were more involved in the development of nursing policies, it a positive influence on patient care could occur.

In this context, Al-Faouri, Ali \& Essa (2014) conducted a study about perception of shared governance among registered nurses in a Jordanian University Hospital. The study emphasized on several factors that were essential to the success of a shared governance program, including support from managers and leaders, clear role delineation, and support for the time nurses need to participate.

Also, Jacobs \& wards (2012) highlighted that the flexibility for nurses to participate in different decisions leads to increased participation and strength of shared governance structure in study about empowering frontline nurses to transform shared governance.

\section{Conclusion}

The current study highlighted that the studied hospital has a traditional governance structure in which staff nurses were not involved in decisionmaking that make them feel control over their professional practice. A gap was identified for their participation in organizational decisions and professional development.

\section{Recommendations}

\section{Based on study findings the following were recommended:}

Top managers should play an important role in supporting the presence of nurses at all levels of decision making and measure patients' and nurses' satisfaction as well as systems' outcomes.

Administrators can adopt the suitable model for shared governance, and develop nurses and nurse managers' abilities for shared governance and decisional involvement.

Nursing administrators can also collaborate with nurses to develop and implement a model of nursing care that supports nurses' professional control over nursing practices.

Furthermore, future research using focus groups to discuss shared governance in particular area of nursing practices to identify challenges that face nurses and nurse managers to allow for necessary interventions to follow.

\section{References}

Al-Faouri, I., Ali, N., \& Essa, M. (2014). Perception of Shared Governance among Registered Nurses in a Jordanian University Hospital. International Journal of Humanities and Social Science, 46(1), 254-262.

Claveile,T., Porter-O'Grady, T., \& Drenkard, K. (2013).Structural empowerment and the nursing practice environment in Magnet organizations. Journal of Nursing Administration, 43(11), 566-573.

Cohen, C.(2015). Leveraging the power of shared governance. Published Doctorate Dissertation. College of Health Sciences, Walden University.

Hess, R. (2010). The measurement of professional governance: Scoring guidelines and benchmarks [instrument manual]. Voorhees, NJ: Forum for Shared Governance.

Hess, R. G. (1994). Measuring Nursing Governance. Nursing Research, 47(1), 35-42. 
Hess, R., DesRoches, C., Donelan, K., et al. (2011). Perceptions of nurses in Magnet hospitals, non-Magnet hospitals, and hospitals pursuing Magnet status. Journal of Nursing Administration, 41(7/8): 315323.https://doi.org/10.1097/NNA.0b $013 \mathrm{e} 31822509 \mathrm{e} 2$.

Jacobs, C., \& Ward, C. (2012). Empowering frontline nurses to transform shared governance. Nursing, 42(7), 18-20. https://doi.org/10.1097/01.NURSE.0 000415321.70217.0d

Jones ,DW.(2017). Shared Governance and Organizational Commitment Reported by Enrollment Managers in the Council of Christian Colleges and Universities. Published Doctorate Dissertation. Arkansas State University.

Jones, C., Irvine, F., \& Sambrook, S. (2010). Empowerment of nursing students in clinical practice: spheres of influence. Journal of Advanced Nursing , 66 (9), 2061-2070.

Jordan, B. (2016). Designing a unit practice council structure. Nursing Management, 47(1), 15- 18.

Keane, A. (2016): The Relationship between Nurse Manager Leadership Style and Enculturation of Shared Governance .Doctoral dissertation .College of Management and Technology.Walden University.

Kieft R, Brouwer B, Francke A, et al.,(2014) How nurses and their work environment affect patient experiences of the quality of care: a qualitative study. BMC Health Services Research14(1), 249.https://doi.org/10.1186/14726963-14-249

Mahmoud, H. (2016).The relationship between nurses' professional shared governance and their work empowerment at Mansoura University and Specialized Medical Hospitals. Journal of Biology, Agriculture and Healthcare, 6(18), 13-21.

Mathias, I. (2015). Shared governance teaches staff to take ownership of decision making. OR Manager.Retrievedfrom http://web.a.ebscohost.com/ehost/ detail/detail?vid=2\&sid=41bf6ac289fb-4d2c-aabl-

Seada, A., \& Etway, E. (2012).Relationship between staff nurses' perception of professional shared governance and their job satisfaction. Journal of American Science, 8(5), 199-208.

Swihart, D., \& Hess, R. (2014). Shared governance:Apracticalapproach totransforming interprofessional healthcare (3rd Ed.).

Toussaint, J., \& Gerard, R. A. (2010). On the mend: Revolutionizing healthcare to save lives and transform the industry. Cambridge, MA: Lean Enterprises Institute.

Wilson, E. (2013). Evaluating shared governance for nursing excellence. Published Doctorate Dissertation. University of Nevada, Las Vegas.

World Health Organization,(2012). Egypt Nursing Profile. WHO country office for Egypt.Availablefrom: http://www.emro.who.int/countries /egy/index.html. 